\title{
Peculiarities of lung cancer clinical course in woman comparing with men
}

\section{Abstract}

Introduction: In recent years there has been a redistribution of the lung cancer (LC) frequency in groups of different sexes according to the histological variants, localization of the disease and dissemination.

\begin{abstract}
Aim: to evaluate the sexual dimorphism of the lung cancer (LC) clinical course, to reveal peculiarities of lung cancer clinical course in woman comparing with men.
\end{abstract}

Patients and methods: there were $1071 \mathrm{LC}$ patients under observation at the National Cancer Institute (Kyiv) from 2000 to 2015, which were included in the main object of the study. Among these patients there were 887 (82.8\%) men and $184(17.2 \%)$ women, at the age of $59.7 \pm 0.32$ years and $57.0 \pm 0.89$ years, respectively.

Results: The patients' sex has an effect on the integral parameters of the LC course, the localization of the tumor process and the nature of the complications. The side of the lung lesions, localization in lobes, the form of the disease, the histological variant of LC and its staging, the development of small cell cancer, adenocarcinoma and squamous cell carcinoma depend on the sex of the patients. Women had more often middle lobe right lung lesion and upper lobe localization of both lungs. Women were 52\% more likely to have IV lung cancer stage; the germination of LC in the ribs was not observed in women at all, and the compression syndrome and tracheal injury accordingly appeared less often at $52 \%$ and $72 \%$, whereas pleurisy was observed 2.2 times more often. Metastasis in women was observed 27 times more often in the thyroid gland, 16.5 times - in the abdominal wall, 2.2 times - in the brain. The metastatic lesion of the skeleton (the so-called "bone form of the LC") was the prerogative of women. Adenocarcinoma of the upper lobe diagnosed in women 2.2 times more often, and squamous cell carcinoma - 2 times less often. Female sex has an effect on metastases in the mediastinal and inguinal lymphatic nodes, lung, thyroid and spine. The gender parameters of survival in men and women were the same.

Conclusions: the course of the LC in woman has its own dimorphism, which is a risk factor for a severe tumorous process

Keywords: cancer, lung, women, dimorphism
Volume 7 Issue 3 - 2018

\section{Oleh Syniachenko,' Yelyzaveta Yehudina, ${ }^{2}$ Oleksii Khaniukov, ${ }^{3}$ Oksana Stoliarova,' Fylypp Stepko' \\ 'Donetsk National Medical University, Ukraine \\ ${ }^{2}$ Dnepropetrovsk Medical Academy, Ukraine \\ ${ }^{3}$ National Cancer Institute, Ukraine}

Correspondence: Yehudina Ye D, PhD in Medicine,Associate Professor, Department of internal medicine 3, Dnipropetrovsk Medical Academy,V.Vernadskogo str., Dnipro, 49000, Ukraine, Tel +38(099)0595475, Email elizavetaegudina@gmail.com

Received: June 22, 2018 | Published: June 26, 2018

\section{Introduction}

The ratio of the lung cancer (LC) prevalence among women and men declined from 1:5-1:4 to $1: 2$, what is more, this frequency rate distribution is decreasing annually. ${ }^{1}$ The LC incidence among women increased by more than three times in the past decade, ${ }^{2}$ they have also increased mortality rates. ${ }^{3}$ The proportion of the LC prevalence in the world is projected to rise in favor of increasing the number of women and reducing men by $2020 .{ }^{4}$ There is a belief that the LC prevalence will be approximately the same in the representatives of different sex in some regions of the globe in the near future.

Sexual dimorphism of the LC course is observed alongside with the number of sick women increase, 6,7 the female sex is an unfavorable risk factor, 8 while the male sex is a prognosis negative predictive factor for the frequency and severity of the skeleton metastasis.9 However, according to YF He et al.,10 MF Oliveira et al.,11 there are no gender specific features of the so-called "bone" form of LC. In recent years there has been a redistribution of the LC frequency in groups of different sexes according to the histological variants of the disease.6,12 And if among all LC patients 5-year survival is about $10 \%$ now, then in women group this figure is significantly worse. 13,14 It should be noted that the annual mortality from LC among men increases on average of $6 \%$, then among women - of $16 \% .^{15}$

The aim of this study was to evaluate the sexual dimorphism of the LC clinical course.

\section{Material and methods}

The research was carried out in accordance with the ethical norms set forth in the Helsinki Medical Assembly Declaration; the patients gave informed consent for the study, which was approved by the bioethics commission of Donetsk National Medical University. There were 1071 LC patients under observation at the National Cancer Institute (Kiev) from 2000 to 2015, which were included in the main object of the study. Among these patients there were 887 (82.8\%) men and $184(17.2 \%)$ women, at the age of $59.7 \pm 0.32$ and $57.0 \pm 0.89$ years, respectively (the age of men was significantly higher $-\mathrm{t}=3.27$, $\mathrm{p}=0.001)$. None of the LC patients had previously been operated on, and after the diagnosis, all patients received radiotherapy, and $73.1 \%$ of them had combined radiotherapy. The grade of tumor differentiation (GDT) and its stage (STT) was evaluated, the integral index of the tumor process severity (ITS) was calculated according to the formula:

$$
\text { ITS }=\ln \left[\mathrm{T}+\mathrm{N}^{2}+(\Sigma \mathrm{M})^{2}\right],
$$

where $\ln$ is the decimal logarithm, $\mathrm{T}$ is the international indicator of the primary tumor nature, $\mathrm{N}$ is the international metastatic index of gional lymph nodes, ${ }^{15,16} \Sigma \mathrm{M}$ is the metastase sum in distant organs.

Diagnosis of LC and its metastases was based on clinical, radiological (X-ray, computer tomography, sonographic, PET), fibroscopic, cytological (histological) methods of investigation. For the diagnosing of the disease we used such apparatus as: Multix-Compact- 
Siemens (Germany), Somazom-Emotion-6-Siemens (Germany), Gygoscan-Intera-Philips (Netherlands), the cyclotron Siemens-RDSEclipse-RD (Germany), combined tomography PET/CT «Biograph64-TruePoint-Siemens (Germany), fibroesophagogastroscope» Olympus-GIF-Q20 «(Japan) and sonographer « Envisor-Philips «(Netherlands). Statistical processing of the obtained results was performed using computer variance, nonparametric, correlation, regression, single (ANOVA) and multivariate (ANOVA / MANOVA) dispersion analysis ("Microsoft Excel" and "Statistica-Stat-Soft", USA programs). We estimated the average values (M), their standard errors and deviations (SD), the parametric correlation coefficients of Pearson and the nonparametric of Kendall, the criteria of Brown-Forsythe and Wilcoxon-Rao dispersion, Student and McNemar-Fisher's test, and the reliability of the statistical indices. The critical significance level for checking the statistical hypotheses was considered to be 0,05 in this study.

\section{Results}

The upper lobes localization of the lung lesion was established in $27.0 \%$ of cases, the lower lobe - in $15.3 \%$, the upper lower localization on the left - in $18.7 \%$, the upper middle - in $25.0 \%$, the lower middle - in $1.4 \%$, the middle lobe - in $3.7 \%$. The mediastinal variant of the disease was noted in $8.9 \%$ of the patients' number, and in $1.2 \%$ of men the apex tumor of Pancoast-Tobias was diagnosed. The central form of LC was noted in $78.7 \%$ of the examined patients, the peripheral in $21.3 \%$, small-cell histological variant of the disease was detected in $17.6 \%$ of cases, and non-small cell - in $82.5 \%$ (adenocarcinoma, squamous and large cell carcinoma in the ratio $3: 3: 1$ ). The ratio IAIB, IIA-IIB, IIIA, IIIB and IV stages of the disease was 1: 2: 23: 35 : 36. GDT was $1.19 \pm 0.038$ points, STT was $5.87 \pm 0.032$ r.u., ITS was $2.85 \pm 0.024$ r.u.

According to Wilcoxon-Rao multivariate analysis of variance, the patients' sex has an effect $(\mathrm{p}<0.001)$ on the integrated parameters of LC course $(\mathrm{WR}=33.62)$, tumor side $(\mathrm{WR}=38.89)$ and the nature of complications ( $\mathrm{WR}=4.41)$. As evidenced by a single-factor variance analysis, the side of the lung lesions $(\mathrm{D}=10,44)$, the localization in lobe $(\mathrm{D}=10,17)$, the form of the disease $(\mathrm{D}=102,10)$, the histological variant of $L C(D=12.47)$ and its staging $(D=4.80)$, as well as the development of small cell cancer $(\mathrm{D}=12.16)$, adenocarcinoma $(\mathrm{D}=$ $81.92)$ and squamous cell carcinoma $(\mathrm{D}=36.23)$ depend on patients' sex.

The bilateral process occurred only in men group. In general, gender specificities related to the tumor lesion side $\left(\chi^{2}=14,45\right.$, $\mathrm{p}=0,001)$, and, as McNamara-Fisher non-parametric analysis shows, in men $64 \%$ more often observed left-sided LC $\left(\chi^{2}=16,76, p<0,001\right)$, whereas in women $-31 \%$ more often the right lung was affected $\left(\chi^{2}=19,49, p<0,001\right)$. As can be seen from Table 1, in men: the upper lower lobe left lung lesion was observed 4 times more often $\left(\chi^{2}=25,64\right.$, $\mathrm{p}<0,001)$ and 3 times the mediastinal form of $\mathrm{LC}\left(\chi^{2}=9,27, \mathrm{p}=0,002\right)$, and in women in 2,6 times more often detected a lesion of the middle lobe $\left(\chi^{2}=9,27, \mathrm{p}=0,002\right)$, by $72 \%$ upper lobe localization of both lungs $\left(\chi^{2}=23,12, p<0,001\right)$ and $41 \%$ lower lobe $\left(\chi^{2}=3,94, p=0,047\right)$.

Table I Gender differences in the different LC localization and histological variant

\begin{tabular}{|c|c|c|c|c|c|c|}
\hline \multirow{3}{*}{ Indices } & \multicolumn{4}{|l|}{ Sex } & \multirow{2}{*}{\multicolumn{2}{|c|}{ Differences }} \\
\hline & \multicolumn{2}{|c|}{ men $(n=887)$} & \multicolumn{2}{|c|}{ women $(n=\mid 84)$} & & \\
\hline & abs. & $\%$ & abs. & $\%$ & $\chi^{2}$ & $\mathbf{p}$ \\
\hline \multicolumn{7}{|l|}{ Lesion side: } \\
\hline right & 505 & 56,9 & 137 & 74,5 & 19,49 & $<0,00$ I \\
\hline left & 370 & $4 I, 7$ & 47 & 25,5 & 16,76 & $<0,00$ I \\
\hline bilateral & 12 & $\mathrm{I}, 4$ & - & - & 2,52 & 0,113 \\
\hline \multicolumn{7}{|l|}{ Lesion localization: } \\
\hline upper lobe & 213 & 24,0 & 76 & $4 I, 3$ & 23,12 & $<0,001$ \\
\hline middle lobe & 26 & 2,9 & 14 & 7,6 & 9,27 & 0,002 \\
\hline lower lobe & 127 & 14,3 & 37 & 20,1 & 3,94 & 0,047 \\
\hline upper lower lobe & 190 & 21,4 & 10 & 5,4 & 25,64 & $<0,001$ \\
\hline middle upper lobe & 227 & 25,6 & 41 & 22,3 & 0,89 & 0,346 \\
\hline middle lower lobe & 15 & $\mathrm{I}, 7$ & - & - & 3,16 & 0,076 \\
\hline mediastinal & 89 & 10,0 & 6 & 3,3 & 8,65 & 0,003 \\
\hline \multicolumn{7}{|l|}{ Histological form: } \\
\hline small celled & 172 & 19,4 & 16 & 8,7 & 12,05 & 0,001 \\
\hline adenocarcinoma & 292 & 32,9 & 124 & 67,4 & 76,23 & $<0,00$ I \\
\hline squamous & 331 & 37,3 & 27 & 14,7 & 35,11 & $<0,00$ I \\
\hline large cell & 92 & 10,4 & 17 & 9,2 & 0,21 & 0,644 \\
\hline
\end{tabular}


In the men's group, the ratio of small cell and non-small cell lung cancer was 1: 4, and among female patients - 11: $1\left(\chi^{2}=12,05, \mathrm{p}=0,001\right)$. Sexual dimorphism is 2.5 times more often in the development of squamous cell carcinoma in men $\left(\chi^{2}=35,11, \mathrm{p}<0,001\right)$ and 2.1 times more rarely in the formation of adenocarcinoma $\left(\chi^{2}=76,23, p<0,001\right)$ which is reflected in Table 1 and in Figure 1. The ratio of the central to the peripheral form of LC in the male group was 5: 1, and in women as $1: 1\left(\chi^{2}=93,37, p<0,001\right)$.
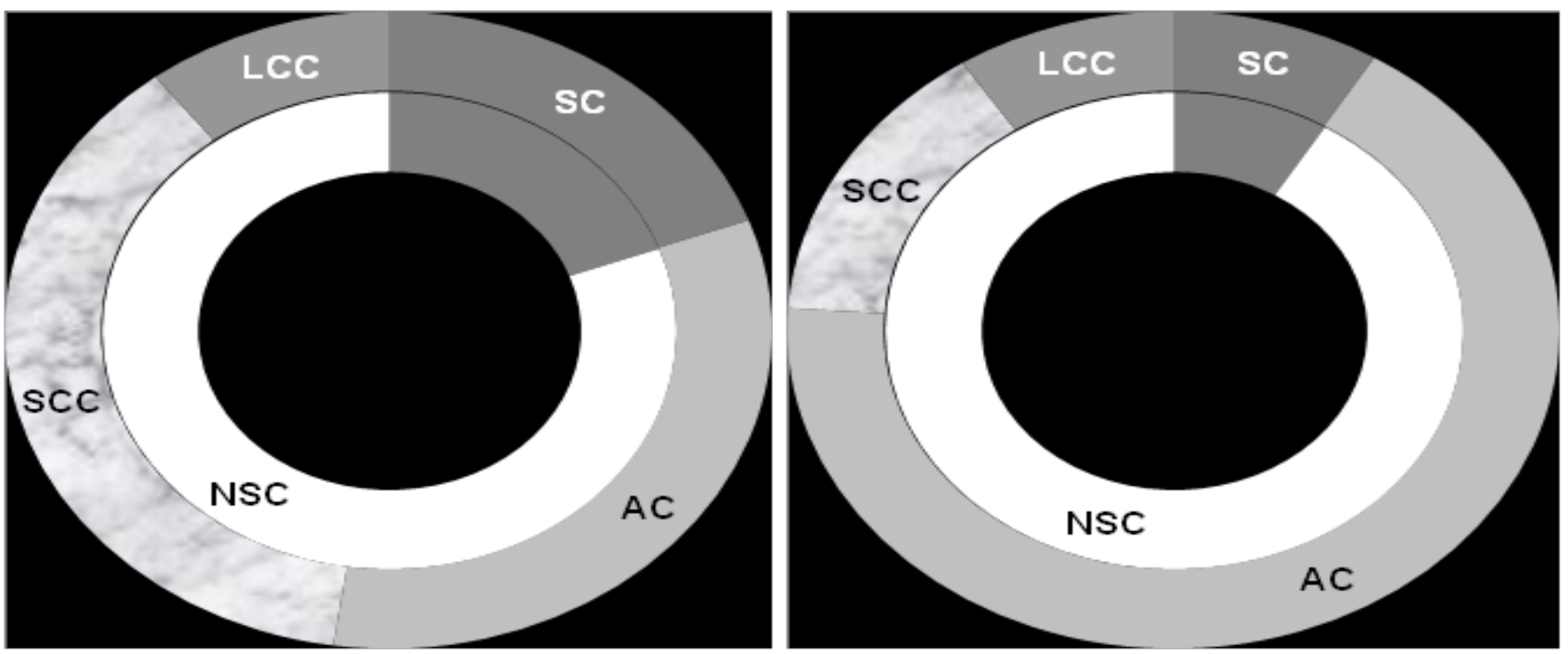

Figure I Distribution of patients with different sex according to histological forms of LC.

Note. SC - small cell LC, NSC - non-small cell LC,AC - adenocarcinoma, SCC - squamous cell carcinoma, LCC- large cell carcinoma.

\section{Discussion}

The gender specific features of LC are caused by complex influences on the pathological process of developing hypoestrogenemia in postmenopausal women and the estrogen / androgen imbalance in men, ${ }^{17}$ inhibition of estrogen receptions. ${ }^{18}$ Certain significance is attached to mutations of some genes in lung adenocarcinoma, which is observed in $9 \%$ of the sick women number and only $3 \%$ of men. ${ }^{19}$ There is sexual dimorphism with respect to the staging of
LC $\left(\chi^{2}=23,41, p=0,001\right)$. For example, in men, IIIB STT $\left(\chi^{2}=16,98\right.$, $\mathrm{p}<0,001)$ was 2.2 times more often, and in women IV STT occurred by $52 \%\left(\chi^{2}=19,05, p<0,001\right)$. These data are presented in Figure 2 . As can be seen from Table 2, the average GDT and ITS in men and women differ little from each other (correspondingly, $1.16 \pm 0.041$ points and $1.34 \pm 0.100$ points, $2.84 \pm 0.026$ r.u. and $2.94 \pm 0.062$ r.u.), while STT values in women were significantly higher $(5.84 \pm 0.034$ r.u. and $6.03 \pm 0.022$ r.u., $t=2.25, \mathrm{p}=0.025$ ).

Table 2 Gender features of the metastases number in LC patients

\begin{tabular}{lllll}
\hline \multirow{2}{*}{ Metastases localization } & Sex & & \multicolumn{2}{l}{ Differences } \\
\cline { 2 - 5 } & men $(\mathbf{n}=\mathbf{8 8 7})$ & women $(\mathbf{n}=\mathbf{1 8 4})$ & $\mathbf{t}$ & $\mathbf{P}$ \\
\hline In lymph nodes & $\mathrm{I}, 59 \pm 0,034$ & $\mathrm{I}, 47 \pm 0,067$ & $\mathrm{I}, 42$ & 0,157 \\
In distant organs & $\mathrm{I}, 34 \pm 0,039$ & $\mathrm{I}, 44 \pm 0,102$ & $\mathrm{I}, 13$ & 0,262 \\
In skeleton & $\mathrm{I}, 92 \pm 0,089$ & $2,32 \pm 0,168$ & 2,28 & 0,024 \\
\hline
\end{tabular}

According to ANOVA, the sex of patients affects the exudative pleurisy development ( $D=18,20, p<0,001)$, tumor germination in the trachea $(\mathrm{D}=8,00, \mathrm{p}=0,005)$ and ribs $(\mathrm{D}=5,77, \mathrm{p}=0,017)$, as well as on the appearance of compression syndrome $(\mathrm{D}=3.99, \mathrm{p}=$ 0.046), which is shown in Figure 3. Germination of the LC into the ribs was not observed in women at all, and compression syndrome and tracheal injury respectively appeared less frequently by $52 \%$ and $72 \%$, whereas pleurisy was observed 2.2 times more often.

According to the performed ANOVA / MANOVA we had such results as: the sex of LC patients has a highly significant $(\mathrm{p}<0.001)$ effect on the metastases character in the lymph nodes (WR $=6.03$, $\mathrm{p}<0.001)$, distant organs (WR $=4.12$ ) and osteoarticular apparatus
$(\mathrm{WR}=4.51)$. According to ANOVA, the number of metastases to distant organs $(\mathrm{D}=2.96, \mathrm{p}=0.019)$ and the skeleton $(\mathrm{D}=8.31, \mathrm{p}$ $<0.001$ ) depends on the patients' sex. Bone and joint metastases had $16+5(18.5 \%)$ men and $69(37.5 \%)$ women $\left(\chi^{2}=32,25, \mathrm{p}<0,001\right)$ and the mean number of LC metastases in the skeleton in women was $21 \%$ more often $(\mathrm{t}=2.28, \mathrm{p}=0.024)$, which is shown in Table 3 .

As can be seen from Table 4, the patients' sex affects the frequency of metastases development in the mediastinal, inguinal and subclavian lymph nodes.

In the women group LC dissemination to the kidney was never observed, whereas it was noted in $15(2.1 \%)$ of men $\left(\chi^{2}=4,01\right.$, 
$\mathrm{p}=0,045$ ), which is reflected in Table 5. In turn, sexual dimorphism of the disease manifested more frequent (by 27 times) development of metastases in the thyroid $\left(\chi^{2}=18,56, p<0,001\right)$, in 16,5 times more often in the abdominal wall $\left({ }^{2}=18,94, p<0,001\right), 2.2$ times - in the brain $\left(\chi^{2}=12,03, p=0,001\right)$. The metastatic lesion of the skeleton (the socalled "bone form of the LC") was the prerogative of women (Table $5)$. Thus, if the metastases to the femoral bone appeared 3.7 times more often in the male group $\left(\chi^{2}=3,93, p=0,047\right)$, then the incidence of metastasis in the ribs predominated in women (1.9 times more often, $\left.\chi^{2}=7,57, \mathrm{p}=0,006\right), 4.1$ times in the scapula $\left(\chi^{2}=7,76, \mathrm{p}=0,005\right), 2.5$ times in the cervicothoracic and lumbar spine $\left(\chi^{2}=28,07, \mathrm{p}<0,001\right)$, 4.2 times in the sacral region $\left(\chi^{2}=27,09, \mathrm{p}<0,001\right), 4.5$ times in the pubic bone $\left(\chi^{2}=7,64, \mathrm{p}=0,006\right), 3.8$ times in the iliac bone $\left(\chi^{2}=29,71\right.$, $\mathrm{p}<0,001), 4.1$ times in the sacroiliac joint $\left(\chi^{2}=19,13, \mathrm{p}<0,001\right), 2.4$ times in the hip joints $\left(\chi^{2}=6,24, \mathrm{p}=0,013\right)$, and the jaw lesion took place only in women $\left(\chi^{2}=14,51, \mathrm{p}<0,001\right)$. In the group of women, the gender features of the LC course were as follows. The LC form (central, peripheral) affected the appearance of obturation atelectasis $(\mathrm{D}=5.20, \mathrm{p}=0.024)$, compression of the superior vena cava $(\mathrm{D}=$ $4.78, \mathrm{p}=0.030)$, metastasis to supraclavicular $(\mathrm{D}=6.53, \mathrm{p}=0.011)$ and cervical lymph nodes ( $\mathrm{D}=6.96, \mathrm{p}=0.009$ ); localization of the tumor process influenced the germination in the trachea $(\mathrm{D}=8.23$, $\mathrm{p}=0.005)$, ileac metastasis $(\mathrm{D}=17.60, \mathrm{p}<0.00)$ and sacrum bone $(\mathrm{D}=9.57, \mathrm{p}=0.002)$; squamous cell carcinoma of LC affects the recurrent nerve compression $(\mathrm{D}=8.74, \mathrm{p}=0.004)$, development of metastases in the pubic bone $(\mathrm{D}=4.52, \mathrm{p}=0.035)$; large cell carcinoma contribute to tumor germination into the esophagus ( $D=22.03$, $\mathrm{p}<0.001)$ and dissemination into the humeral bone $(\mathrm{D}=4.35, \mathrm{p}=$ $0.038)$; and adenocarcinoma - into the femur $(\mathrm{D}=4.09, \mathrm{p}=0.045)$. Gender parameters of the patients' survival were the same in men and women, and 3-year survival rate was respectively $24 \%$ and $25 \%$. As shown by ANOVA, sexual dimorphism LC was characterized by a significant effect of the pathological process localization in men on the life duration $(\mathrm{D}=1.47, \mathrm{p}=0.026)$, the form of the disease $(\mathrm{D}=$ $1.41, \mathrm{p}=0.042)$, the presence of exudative tumoral pleurisy $(\mathrm{D}=2.55$, $\mathrm{p}<0.001)$, tumor germination into the trachea $(\mathrm{D}=1.51, \mathrm{p}=0.018)$, esophagus $(\mathrm{D}=1.53, \mathrm{p}=0.015)$ and chest wall $(\mathrm{D}=2.08, \mathrm{p}<0.001$ $(D=3.69, p<0.001)$, and in women - small cell variant of $L C(D=3,69$, $\mathrm{p}<0,001)$, compression syndrome $(\mathrm{D}=3.02, \mathrm{p}<0.001)$, and obturation atelectasis $(\mathrm{D}=4.90, \mathrm{p}<0.001)$.
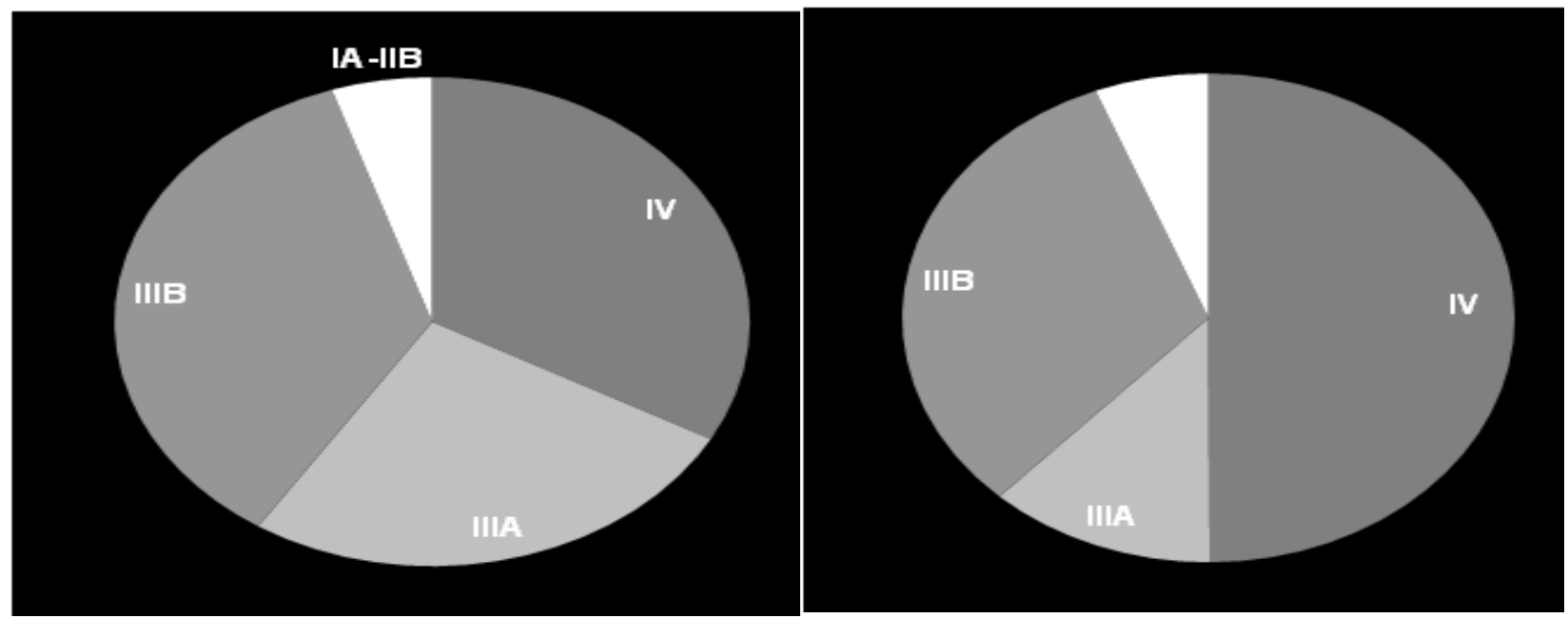

Figure 2 Distribution of different sexes patients by stages of LC.

Note. Left - men, right - women.

Table 3 Gender features of the lymph nodes metastases frequency in LC patients

\begin{tabular}{|c|c|c|c|c|c|c|}
\hline \multirow{3}{*}{ Lymph node groups } & \multicolumn{4}{|l|}{ Sex } & \multirow{2}{*}{\multicolumn{2}{|c|}{ Differences }} \\
\hline & \multicolumn{2}{|c|}{ men $(n=887)$} & \multicolumn{2}{|c|}{ women $(n=184)$} & & \\
\hline & abs. & $\%$ & abs. & $\%$ & $\chi^{2}$ & $\mathrm{p}$ \\
\hline Mediastinal & 630 & 71,0 & 89 & 48,4 & 35,45 & $<0,001$ \\
\hline Supraclavicular & 145 & 16,4 & 35 & 29,0 & 0,78 & 0,377 \\
\hline Subclavian & 13 & I,5 & 9 & 4,9 & 8,89 & 0,003 \\
\hline Cervical & 62 & 7,0 & 15 & 8,2 & 0,31 & 0,579 \\
\hline Axillary & 23 & 2,6 & 6 & 3,3 & 0,26 & 0,612 \\
\hline Submandibular & 6 & 0,7 & - & - & 1,25 & 0,263 \\
\hline Bronchopulmonary & 190 & 21,4 & 29 & 15,8 & 3,00 & 0,083 \\
\hline Bifurcation & 54 & 6,1 & 6 & 3,3 & 2,30 & 0,129 \\
\hline Inguinal & 4 & 0,5 & 7 & 3,8 & 16,86 & $<0,001$ \\
\hline Mesenterial & 11 & $\mathrm{I}, 2$ & I & 0,5 & 0,67 & 0,414 \\
\hline Retroperitoneal & 19 & 2,1 & 2 & $\mathrm{I}, \mathrm{I}$ & 0,88 & 0,348 \\
\hline
\end{tabular}


Table 4 Gender features of the distant organ metastases frequency in the LC patients

\begin{tabular}{|c|c|c|c|c|c|c|}
\hline \multirow{3}{*}{ Organs } & \multicolumn{4}{|l|}{ Sex } & \multirow{2}{*}{\multicolumn{2}{|c|}{ Differences }} \\
\hline & \multicolumn{2}{|c|}{ men $(n=887)$} & \multicolumn{2}{|c|}{ women $(n=\mid 84)$} & & \\
\hline & abs. & $\%$ & abs. & $\%$ & $x^{2}$ & $\mathrm{p}$ \\
\hline Lung & 128 & 14,4 & 35 & 19,0 & 2,49 & 0,115 \\
\hline Skin & II & $\mathrm{I}, 2$ & 5 & 2,7 & 2,26 & 0,133 \\
\hline Thyroid & 1 & 0,1 & 5 & 2,7 & 18,56 & $<0,001$ \\
\hline Aorta & 9 & 1,0 & - & - & $\mathrm{I}, 88$ & 0,170 \\
\hline Heart & 13 & 1,5 & - & - & 2,73 & 0,099 \\
\hline Brain & 55 & 6,2 & 25 & 13,6 & 12,03 & 0,001 \\
\hline Eye & - & - & 2 & $\mathrm{I}, \mathrm{I}$ & 9,66 & 0,002 \\
\hline Kidney & 15 & 2,1 & - & - & 4,01 & 0,045 \\
\hline Adrenal & 31 & 2,5 & 5 & 2,7 & 0,28 & 0,594 \\
\hline Abdominal wall & 2 & 0,2 & 6 & 3,3 & 18,94 & $<0,001$ \\
\hline Liver & 77 & 8,7 & 16 & 8,7 & 0,01 & 0,995 \\
\hline Intestine & 7 & 0,8 & - & - & $\mathrm{I}, 46$ & 0,227 \\
\hline Pancreas & 14 & 1,6 & 3 & $\mathrm{I}, 6$ & 0,01 & 0,959 \\
\hline
\end{tabular}

Table 5 Gender features of the metastases frequency in the osteo-articular apparatus in LC patients

\begin{tabular}{|c|c|c|c|c|c|c|}
\hline \multirow{3}{*}{ Bones, joints } & \multicolumn{4}{|l|}{ Sex } & \multirow{2}{*}{\multicolumn{2}{|c|}{ Differences }} \\
\hline & \multicolumn{2}{|c|}{ men $(n=887)$} & \multicolumn{2}{|c|}{ women $(n=184)$} & & \\
\hline & abs. & $\%$ & abs. & $\%$ & $\chi^{2}$ & $\mathbf{p}$ \\
\hline Skull & 4 & 0,5 & - & - & 0,83 & 0,361 \\
\hline Sternum & II & 1,2 & 2 & $\mathrm{I}, \mathrm{I}$ & 0,03 & 0,863 \\
\hline Ribs & 55 & 6,2 & 22 & 12,0 & 7,57 & 0,006 \\
\hline Jaws & - & - & 3 & 1,6 & $|4,5|$ & $<0,001$ \\
\hline Clavicles & 8 & 0,9 & 2 & $\mathrm{I}, \mathrm{I}$ & 0,06 & 0,812 \\
\hline Scapula & 7 & 0,8 & 6 & 3,3 & 7,76 & 0,005 \\
\hline Elbow joints & 3 & 0,3 & - & - & 0,62 & 0,430 \\
\hline Humeral bones & 21 & 2,4 & 5 & 2,7 & 0,08 & 0,779 \\
\hline Shoulder joints & 15 & $\mathrm{I}, 7$ & 4 & 2,2 & 0,20 & 0,652 \\
\hline Knee joints & 2 & 0,2 & - & - & 0,42 & 0,519 \\
\hline Spine & 78 & 8,8 & $4 I$ & 22,3 & 28,07 & $<0,00$ I \\
\hline Pubic bone & 5 & 0,6 & 5 & 2,7 & 7,64 & 0,006 \\
\hline Ilium & 30 & 3,4 & 24 & 13,0 & 29,71 & $<0,00$ I \\
\hline Sacrum & 23 & 2,6 & 20 & 10,9 & 27,09 & $<0,001$ \\
\hline Sacral-ileal joints & 18 & 2,0 & 15 & 8,2 & 19,13 & $<0,00$ I \\
\hline Femur bones & 36 & 4,1 & 2 & $\mathrm{I}, \mathrm{I}$ & 3,93 & 0,047 \\
\hline Hip joints & 22 & 2,5 & 11 & 6,0 & 6,24 & 0,013 \\
\hline Tibias & 8 & 0,9 & - & - & 1,67 & 0,196 \\
\hline Ankle joints & 2 & 0,2 & - & - & 0,42 & 0,519 \\
\hline
\end{tabular}



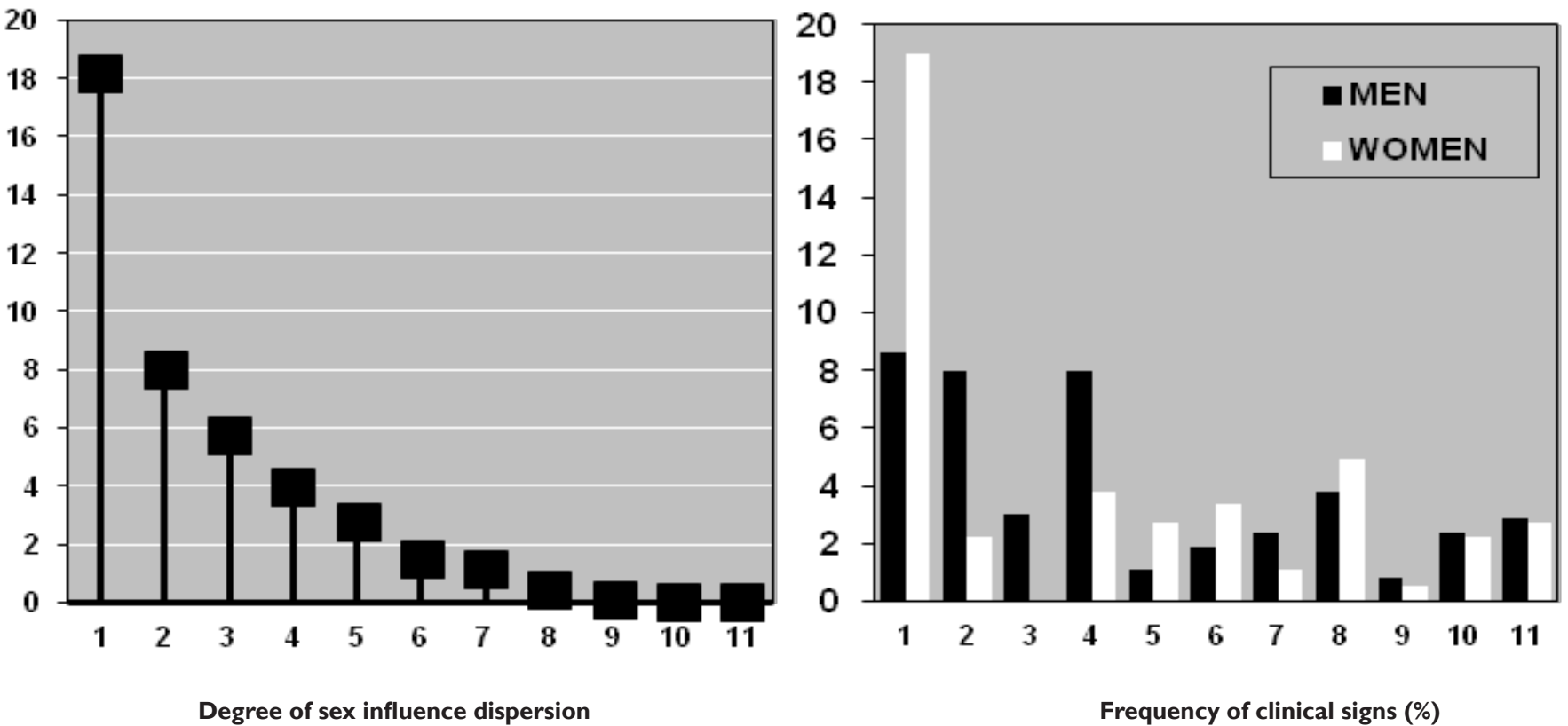

Figure 3 Gender features of LC clinical manifestations.

Frequency of clinical signs (\%)

Note. I - exudative pleurisy, 2 - tumor germination in the trachea, 3 - tumor germination in the ribs, 4 - compression syndrome, 5 - compression of the superior vena cava, 6 - mediastinum lesion, 7 - tumor germination in the esophagus, 8 - obturation atelectasis, 9 - tumor germination in the pericardium, 10 - tumor germination in the thoracic wall, II - compression of the recurrent nerve.

The gender features of the upper lobe LC were further analyzed, in which the sexual dimorphism of this localization is noted in the literature. ${ }^{6,7}$ All patients suffering from large cell carcinoma in the upper lobes turned out to be males, whereas adenocarcinoma was 2.2 times more often diagnosed in women, and squamous cell carcinoma was 2 times less frequent $\left(\chi^{2}=108,92, p<0,001\right)$. Sexual dimorphism is absent in relation to regional complications of the disease and the nature of metastasis in the lymph nodes. In women, only exudative pleurisy (11.1\% of LC cases) occurred and in 1 case, the tumor dissemination into the chest wall. According to ANOVA, the patients' sex affects metastases in the mediastinal and inguinal lymph nodes (D $=3.29, \mathrm{p}=0.039$ and $\mathrm{D}=6.27, \mathrm{p}=0.013$, respectively), lung $(\mathrm{D}=$ $6.71, p=0.010)$, the thyroid gland $(\mathrm{D}=12.90, \mathrm{p}<0.001)$ and the spine $(\mathrm{D}=23.53, \mathrm{p}<0.001)$, which is the prerogative of women.

We considered it appropriate to further study the nature of the upper lobe adenocarcinoma course, as the most frequent variant of LC in women. The differentiation degree of this tumor in representatives of different sexes differed little among themselves $(t=1.35, \mathrm{p}=0.185)$. The number of distant metastases $(D=3.78, p=0.013)$, the presence of metastases in the cervical lymph nodes $(\mathrm{D}=5.20, \mathrm{p}=0.025)$, the spine $(\mathrm{D}=10.21, \mathrm{p}=0.002)$ and lungs $(\mathrm{D}=5.58, \mathrm{p}=0.020)$ depended on the patients' sex. The last three metastases localizations were detected in women 8.2 times $\left(\chi^{2}=5,05\right), 3.5$ times $\left(\chi^{2}=9,47\right)$ and 2.8 times $\left(\chi^{2}=5,39\right)$ more often.

\section{Conclusion}

There are gender specific features of the LC course, which are related to the localization of the pathological process (in men more often on the left and in the mediastinum, in women - on the right, locally in the upper, middle and lower lobes), to STT parameters in the manifest of the disease (in women the level is higher), tumor form (prevalence of central in men and peripheral in women), the frequency of squamous cell carcinoma in men and adenocarcinoma in women, metastasis presence in the mediastinal lymph nodes, kidneys, femur, subclavian, inguinal lymph nodes, thyroid gland, brain, eyes, abdominal wall, jaw, clavicle, spine, pubic, sacral, iliac, sacroiliac and hip joints in others, sexual dimorphism of patients' survival is absent. There are the gender peculiarities of the upper lobe LC course: more frequent development of small cell and squamous cell carcinomas in men, but less degree of differentiation of the tumor process, and in women - adenocarcinoma, absence of Pancoast-Tobias cancer, large cell carcinoma, greater frequency of distant metastases (in the lung, spine), as well as STT of adenocarcinoma, while there are no gender specific features of survival of patients with such a localization of LC.

\section{Acknowledgments}

None.

\section{Conflict of interest}

Author declares that there is no conflict of interest.

\section{References}

1. Zhou C. Lung cancer molecular epidemiology in China: recent trend. Transl Lung Cancer Res. 2014;3(5):270-279.

2. Molina AJ, García-Martínez L, Zapata-Alvarado J, et al. Trends in lung cancer Incidence in a healthcare area. Arch Bronconeumol. 2015;4(7):122-127.

3. Vanthomme K, Vandenheede H, Hagedoorn P, et al. Trends in site-and sexspecific cancer mortality between 1979 and 2010 in Belgium compared with Europe using WHO data. J Public Health. 2016;38(2):e68-76.

4. Olajide OO, Field JK, Davies MM, et al. Lung cancer trend in England 
for the period of 2002 to 2011 and projections of future burden until 2020. Int J Oncol. 2015;47(2):739-746.

5. Yu XQ, Kahn C, Luo Q, et al. Lung cancer prevalence in New South Wales (Australia): Analysis of past trends and projection of future estimates. Cancer Epidemiol. 2015;39(4):534-538.

6. Akhtar-Danesh N, Finley C. Temporal trends in the incidence and relative survival of non-small cell lung cancer in Canada: A population-based study. Lung Cancer. 2015;90(1):8-14.

7. Linares I, Molina-Portillo E, Expósito J, et al. Trends in lung cancer incidence by histologic subtype in the south of Spain, 1985-2012: a population-based study. Clin Transl Oncol. 2016;18(5):489-96.

8. Lumachi F, Mazza F, Del Conte A, et al. Short-term survival of patients with lung metastases from colorectal and non-colorectal cancer who underwent pulmonary metastasectomy. Anticancer Res. 2015;35(6):3563-3566.

9. Ulas A, Bilici A, Durnali A, et al. Risk factors for skeletal-related events (SREs) and factors affecting SRE-free survival for nonsmall cell lung cancer patients with bone metastases. Tumour Biol. 2016;37(1):1131-40.

10. He YF, Luo HQ, Wang W, et al. Clinical features and prognosis-associated factors of non-small cell lung cancer exhibiting symptoms of bone metastasis at the time of diagnosis. Oncol Lett. 2015;9(6):2706-2712.

11. Oliveira MF, Rotta JM, Botelho RV. Survival analysis in patients with metastatic spinal disease: the influence of surgery, histology, clinical and neurologic status. Arq Neuropsiquiatr. 2015;73(4):330-335.
12. Meza R, Meernik C, Jeon J, et al. Lung cancer incidence trends by gender, race and histology in the United States, 1973-2010. PLoS One. 2015;10(3):0121323.

13. Salomaa ER, Walta M. The prognosis of lung cancer continues to be poor-treatment outcome within the hospital district of Southwest Finland in 2004 to 2011. Duodecim. 2015;131(1):69-75.

14. Qu HM, Bai YN, Cheng N, et al. Trend analysis of cancer mortality in the jinchang cohort, China, 2001-2010. Biomed Environ Sci. 2015;28(5):364-369.

15. Galaychuk IY. TNM classification of malignant tumours: history, principles, practical application. Oncology. 2010;3:270-275.

16. Bondar GV, Dumanskyi YuV, Popovych AYu. Oncology. Medicine. 2015. $576 \mathrm{p}$.

17. Honma N, Hosoi T, Arai T, et al. Estrogen and cancers of the colorectum, breast, and lung in postmenopausal women. Pathol Int. 2015;65(9):451459

18. Brückl WM, Al-Batran SE, Ficker JH, et al. Estrogen receptors and their impact for prognosis and therapy of lung cancer - new insights to an underestimated mechanism. Pneumologie. 2015;69(6):350-360.

19. Shan L, Qiu T, Ling Y, et al. Prevalence and clinicopathological characteristics of HER2 and BRAF mutation in Chinese patients with lung adenocarcinoma. PLoS One. 2015;10(6):0130447. 